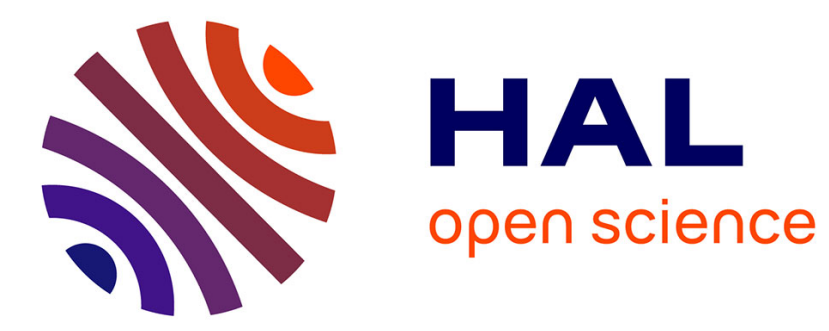

\title{
L-arginine metabolism in dog kidney and isolated nephron segments.
}

Olivier Levillain, Daniel Rabier, Bernard Duclos, Pierrette Gaudreau, Patrick Vinay

\section{- To cite this version:}

Olivier Levillain, Daniel Rabier, Bernard Duclos, Pierrette Gaudreau, Patrick Vinay. L-arginine metabolism in dog kidney and isolated nephron segments.. Metabolism, 2008, 57 (1), pp.9-23. 10.1016/j.metabol.2007.06.001 . hal-00306557

\section{HAL Id: hal-00306557 https://hal.science/hal-00306557}

Submitted on 28 Jul 2008

HAL is a multi-disciplinary open access archive for the deposit and dissemination of scientific research documents, whether they are published or not. The documents may come from teaching and research institutions in France or abroad, or from public or private research centers.
L'archive ouverte pluridisciplinaire HAL, est destinée au dépôt et à la diffusion de documents scientifiques de niveau recherche, publiés ou non, émanant des établissements d'enseignement et de recherche français ou étrangers, des laboratoires publics ou privés. 


\title{
L-Arginine Metabolism in Dog Kidney and Isolated Nephron Segments
}

\author{
Olivier Levillain ${ }^{1}$, Daniel Rabier ${ }^{2}$, Bernard Duclos ${ }^{3}$, \\ Pierrette Gaudreau ${ }^{3}$ and Patrick Vinay ${ }^{3}$
}

\author{
${ }^{1}$ Université Claude Bernard Lyon 1, \\ Laboratoire de Physiopathologie Métabolique et Rénale, \\ Institut National de la Santé et de la Recherche Médicale (INSERM) U 499, \\ 7, rue G. Paradin, 69372 Lyon Cedex 08, France \\ ${ }^{2}$ Laboratoire de Biochimie Médicale B, Hôpital Necker-Enfants malades, 149 Rue de Sèvres, \\ 75743 Paris Cedex 15, France \\ ${ }^{3}$ Nephrology Service, Hôpital Notre-Dame de Montréal, Groupe de Recherche en Transport \\ Membranaire, Université de Montréal, Montréal, Québec, H2L 4M1, Canada
}

short title : L-Arginine Metabolism in Dog Kidney

\section{Correspondence: Dr Olivier LEVILLAIN}

Université Claude Bernard Lyon I

Physiologie Intégrative, Cellulaire et Moléculaire

UMR 5123 CNRS, Bâtiment. R. Dubois

43, Bvd du 11 Novembre 1918

69622 VILLEURBANNE cedex

FRANCE

Phone : 33 (0)4 72431173

Fax : $33(0) 472431172$ 


\begin{abstract}
The renal basic amino acid metabolism often differs in rodents, strict carnivore, and omnivore species. Given the pivotal role of L-arginine and L-ornithine in several metabolic pathways and the fact that the dog is closely related to humain being also an omnivore, we tested whether L-arginine metabolism and L-ornithine catabolism take place in the dog kidney. We examined the metabolic of L-arginine in dog cortical tubules to integrate local L-arginine metabolism into a general physiological and metabolic framework. To achieve these goals, we first ascertained the protein expression of relevant enzymes identified by Western blotting. Larginine catabolism was studied in suspensions of canine cortical proximal tubules, medullary thick ascending limbs, and papillary collecting ducts either incubated without exogenous Larginine being added (small endogenous quantities) or incubated with L-arginine being added in supraphysiological amounts $(2 \mathrm{mmol} / \mathrm{L}$ with or without the presence of alternative metabolic substrates, $2 \mathrm{mmol} / \mathrm{L}$ L-glutamine, or lactate). The results revealed that dog kidneys consumed L-citrulline and released L-arginine and L-ornithine. Argininosuccinate synthetase and lyase, arginase II, and ornithine aminotransferase were detected in the renal cortex. Arginase II activity was found in a suspension of proximal tubules by measuring the amounts of urea and L-ornithine produced. A fraction of this L-ornithine was further partially metabolized through the intramitochondrial ornithine aminotransferase pathway, leading to changes in L-glutamate, glucose, L-alanine, and ammonia metabolism without L-proline accumulation. Medullary thick ascending limbs expressed a very low arginase activity whereas papillary collecting ducts did not. In conclusion, the dog kidney produces L-arginine. Part of this L-arginine is further catabolized by arginase II, suggesting that its physiological role was to produce L-ornithine for the body.
\end{abstract}


Key words: L-citrulline, L-arginine, L-ornithine, dog, proximal convoluted tubules, argininosuccinate lyase, argininosuccinate synthetase, arginase type II, ornithine aminotransferase, plasma, Western blot. 


\section{INTRODUCTION}

The mammalian kidney expresses several enzymes involved in L-arginine anabolism and catabolism [1,2]. The anabolic enzymes, namely, argininosuccinate synthetase (ASS, Enzyme Commission [EC] 6.3.4.5) and argininosuccinate lyase (ASL, EC 4.3.2.1), convert L-citrulline in the presence of L-aspartate and adenosine triphosphate (ATP) into L-arginine and fumarate within 2 steps (Fig. 1). The catalytic, physical, and chemical properties of these enzymes as well as the enzymatic mechanisms have been analyzed in details in kidneys of different species including guinea pig and rat [3]. The contribution of the kidney in L-arginine synthesis was demonstrated by injecting L-[ureido- $\left.{ }^{14} \mathrm{C}\right]$ L-citrulline to rats and by measuring the incorporation of labeled L-arginine into proteins [4]. In rats with intact kidneys, labeled proteins were detected in kidneys, muscle, liver, and brain, whereas, in rats with ligated renal pedicles, the incorporation of radioactivity into proteins was dramatically lowered [4]. In the same way, experiments performed on isolated perfused rat kidney showed a progressive reduction in perfusate $\mathrm{L}$-[ureido- ${ }^{14} \mathrm{C}$ ] L-citrulline associated with a progressive increase in L[guanidino- ${ }^{14} \mathrm{C}$ ] L-arginine [5]. Furthermore, the expression of ASS and ASL genes based on the measurement of their transcripts, proteins, and enzyme activities has been reported during development of rat [6,7] and mouse [8] kidneys as well as in adult rat [9-11] and mouse [12] kidneys. Physiological studies clearly demonstrated the renal synthesis of L-arginine by quantitating arterial and renal venous concentrations of L-citrulline and L-arginine. A net renal uptake of L-citrulline from the blood was closely matched by a release of L-arginine into the bloodstream of control rats [13], rats with 5/6 nephrectomy [14], mongrel dogs [15], mice $[16,17]$, and patients with chronic renal failure [18]. Within the mammalian kidney, ASS and ASL genes are constantly expressed in the cortex, and in a lesser extent, in the outer stripe of the outer medulla $[19,20]$. More detailed studies revealed that these enzymes are localized in the proximal tubule (PT) and exhibit their highest activity in the proximal convoluted tubule (PCT) [8,21-23].

In the kidney, L-arginine catabolism is controlled by several enzymes including arginase type II (AII, EC 3.5.3.1), which hydrolyses L-arginine into urea and L-ornithine, and arginineglycine amidinotransferase (GAT, EC 2.1.4.1), which metabolizes L-arginine and L-glycine into guanidinoacetic acid and L-ornithine (Fig. 1). Although other enzymes metabolizing Larginine are expressed in the kidney, our attention is restricted to AII and GAT. The expression of an arginase gene in the kidney has been reported in rats [24], rabbits [25], mice [26,27], dogs [24,28,29], humans [24,27,30], and other species [24,28,31] (for review, see also [2,31]). 
In the dog kidney, the arginase activity is almost exclusively confined in the cortex compared with the other renal zones [28]. Within the dog cortex, arginase activity was twice higher in the superficial cortex than that in the deep cortex, whereas it was about 40-fold lower in the outer stripe of the outer medulla. In contrast, the red and white medullae were devoid of an arginase activity [28]. In dogs, the renal arginase isoform strongly differs from that of the liver [24]. In another report, it was concluded that the dog kidney is capable of de novo urea synthesis, suggesting the presence of an arginase activity [32]. Given the high cellular heterogeneity in the kidney, the enzyme exhibits a typical distribution pattern of expression along the nephron. The expression of AII is constantly found in the cortical and outer medullary proximal straight tubules and in other nephron segments that varied from a species to another species [19,23,3335]. The expression of GAT has been reported in kidneys of several rodents, dogs [36], and humans [37]. Arginine-glycine amidinotransferase is found in the renal cortex and, in a lesser extent, in the outer stripe of the outer medulla. Detailed studies based on the use of immunological technology and microdissection of the nephron revealed that GAT is expressed only in the PT with the highest activity in the PCT [38,39].

In several species, given that the proximal tubular cells express the enzymes cited above, the steady-state tissular concentration of L-arginine may thus be finely regulated through changes in these opposite fluxes with consequences for the local metabolism of L-arginine and local urea production. In addition, the endogenous production of L-ornithine by AII and GAT as well as the cellular uptake of L-ornithine provide L-ornithine for ornithine decarboxylase (ODC, EC 4.1.1.17), the rate limiting enzyme of the polyamine pathway, and for ornithine aminotransferase (OAT, EC 2.6.1.13), the key enzyme involved in L-glutamate, L-glutamine, and L-proline synthesis.

An abundant literature supports that the renal metabolism of L-arginine and L-ornithine varied from one species to another species. For example, strict canivores such as cats are unable to produce sufficient amounts of L-citrulline to support their metabolic needs in L-arginine [21]. In contrast, dogs are not strict carnivores and can eat less meat than cats. As omnivores, dog metabolism does not strongly differ from that of humans and might constitute an excellent experimental model when human kidneys are not available. At present, L-arginine metabolism is poorly studied in dog kidneys. This statement is supported by the lack of data concerning the renal expression of ASS and ASL genes and the precise identification of the segments of the dog nephron that are involved in L-arginine anabolism and catabolism as well as L-ornithine metabolism. In addition, the metabolic consequences of the expression of ASS, ASL, AII, and GAT on the other metabolic pathways have never been examined in the kidney. 
Therefore, we investigated in vivo L-arginine anabolism in the dog kidney by measuring the concentration of plasma amino acids in the renal vein and abdominal aorta and calculating the renal balance of each L-amino acid. In addition, the expression of ASS and ASL was tested in the different subcellular compartment of the renal dog cortex by Western blot analyses. To determine which nephron segments express AII, L-arginine catabolism was analyzed in 3 representative segments of the dog nephron; and the production of urea and L-ornithine was determined. The metabolic fate of L-ornithine produced by AII and the use of L-arginine as a potential metabolic substrate when omitted from the incubating medium (no L-arginine added), presented in subphysiological (10-50 $\mu \mathrm{mol} / \mathrm{L})$ and physiological quantities $(100-200 \mu \mathrm{mol} / \mathrm{L})$, or when added in supraphysiological amounts $(0.5-2 \mathrm{moml} / \mathrm{L})$ as well as the competition of Larginine with L-glutamine or lactate oxidation at both levels are useful information to integrate the presence of AII activity into a general physiological and metabolic framework.

Our results showed that, in vivo, the dog kidney extracted L-citrulline from the arterial blood and released equimolar amounts of L-arginine in the blood of the renal vein. The functionality of this pathway was confirmed by detecting significant amounts of ASS and ASL proteins in the cortex of dog kidney. Dog PTs efficiently hydrolyzed L-arginine to produce an accumulation of urea and L-ornithine. The functionality of this pathway was supported by the mitochondrial expression of AII in the dog cortex. A small fraction of L-ornithine derived from L-arginine was further converted into L-glutamate by the mitochondrial OAT. The accumulation of L-ornithine in vitro suggested that the release of L-ornithine observed in the renal vein might originate in part from L-arginine. In a general physiological and metabolic framework, (1) dogs are not auxotroph for L-arginine because L-citrulline is available, (2) Larginine metabolism interacted with L-glutamine catabolism, and (3) L-arginine was not a major gluconeogenic substrate in isolated dog PTs. The medullary thick ascending limbs (MTALs) hydrolysed L-arginine at a very low rate, and the collecting duct did not catabolize L-arginine significantly. 


\section{MATERIAL and METHODS}

\subsection{Animals}

Six mongrel dogs used for metabolic studies were anesthetized with $30 \mathrm{mg}$ Nembutal (Clin Midy, Paris, France) per kilogram body weight, (BW). Twenty milliliters of $20 \%$ mannitol was injected intravenously to open the lumen of renal tubules. Five beagle dogs of approximately 18 kilogram BW were used for Western blot and plasma amino acid analyses (a gift from Ecole Vétérinaire, Marcy l'Etoile, France). Dogs were anesthetized by injecting intravenously $20 \mathrm{mg}$ sodium pentobarbital per kilogram BW (Nembutal 18\%, Clin Midy, Paris, France). Sixweek-old female Sprague Dawley rats from Charles Rivers Laboratories (L'Arbresle sur Orge, France) had free access to tap water and standard laboratory food (Souffirat, 20\% protein, Genthon S.A., France) and were housed in a room maintained at $20^{\circ} \mathrm{C}$ with a 12 -hour light/dark cycle. The rats were anaesthetized by injecting intraperitoneally $0.1 \mathrm{~mL} / 100 \mathrm{~g} \mathrm{BW}$ sodium pentobarbital (Nembutal 6\%, Clin Midy). Mongrel dogs were cared for in accordance with the principles and guidelines of the Canadian Council on Animal Care. Rat and beagle dogs care complied with French regulations for the protection of animals used for experimental and other scientific purposes and with European Community regulations. The author is authorised (no. 69-33) to use animals for these experiments.

\subsection{Amino acid determination in arterial and renal venous blood}

Blood was collected in the renal vein of the left kidney and the abdominal aorta of 5 beagle dogs with a 23-gauge needle (Terumo, Neolus, Guyancourt, France) mounted on a $10 \mathrm{~mL}$ syringe (Terumo) heparinized (Heparin, Roche Diagnostics, Meylan, France) 1 day before the experiment and dried at room temperature. The tip of the needle was curved, pushed into the initial portion of the renal vein near the exit of the kidney, pointed toward the kidney, and pushed in the hilus to prevent blood backward surge from vena cava and spermatic vein. Four to five milliliters of blood were collected slowly and regularly at a maximum rate of 5 $\mathrm{mL} / \mathrm{min}$, transferred into lithium heparinized Vacutainer tubes, and maintained at $4^{\circ} \mathrm{C}$. Blood was centrifuged at $11700 \mathrm{~g}$ for 15 minutes at $4^{\circ} \mathrm{C}$ to collect the plasma. Two-hundred microliters of nonhemolyzed plasma were deproteinized by adding $20 \mu \mathrm{L}$ of $30 \%$ sulfosalicylic acid, vortexed, put on ice for 60 minutes, and centrifuged at $11700 \mathrm{~g}$ for $15 \mathrm{~min}$ at $4{ }^{\circ} \mathrm{C}$. The supernatant was collected and frozen at $-80^{\circ} \mathrm{C}$ until amino acid analysis was carried out.

Plasma amino acids were determined in sulfosalicylic deproteinized samples by ion-exchange chromatography using a Jeol AminoTac amino acid analyser according to the manufacturer's 
methodology. Before analysis, samples were half-diluted with a dilution buffer (Jeol) containing 2 amino acid standards: D-glucosaminic acid and 2-aminoethyl cysteine. Plasma from the National Quality Control for amino acid analysis was regularly used to check our method.

\subsection{Preparation of tubule suspension for metabolic studies}

The kidneys were removed, decapsulated, and placed in a modified ice-cold Krebs-Henseleit saline (KHS) composed of $112.7 \mathrm{mmol} / \mathrm{L} \mathrm{NaCl}, 3.3 \mathrm{mmol} / \mathrm{L} \mathrm{KCl}, 1.2 \mathrm{mmol} / \mathrm{L} \mathrm{KH}_{2} \mathrm{PO}_{4}, 1.2$ $\mathrm{mmol} / \mathrm{L} \mathrm{MgSO}_{4}, 0.5 \mathrm{mmol} / \mathrm{L} \mathrm{CaCl}_{2}, 50 \mathrm{mmol} / \mathrm{L}$ mannitol, $25 \mathrm{mmol} / \mathrm{L} \mathrm{NaHCO}_{3}(\mathrm{pH}$ 7.4) at $37^{\circ} \mathrm{C}$ and osmolality at $350 \mathrm{mosm} / \mathrm{kg}$. The superficial cortex, the inner stripe of the outer medulla, and the papilla were dissected with scissors. The tissues were then sliced using a Stadie-Riggs microtome to obtain slices of homogenous thickness. Slices were washed 3 times with ice-cold KHS to remove cell debris. Cortical tubules (> 85\% PTs), MTALs, and papillary collecting ducts (PCDs) were prepared from relevant tissue by collagenase digestion as previously described [40]. After the digestion, the final suspension adjusted to $60 \mathrm{mg}$ wet weight per milliliter was kept at $4{ }^{\circ} \mathrm{C}$ in standard KHS fully gassed with $5 \% \mathrm{CO}_{2}+95 \% \mathrm{O}_{2}$ until utilization [40]. Aliquots of the tubule suspensions were dried to obtain the tissue dry weight after subtraction of the weight due to salts and mannitol contained in KHS.

\subsection{Metabolic behaviour : substrates utilization and metabolites production}

The tubule suspension ( $30 \mathrm{mg}$ wet weight per flask) was incubated at $37^{\circ} \mathrm{C}$ for 30,60 , and 120 minutes (PTs); 60 and 120 minutes (MTALs); and 120 minutes (PCDs) in $4 \mathrm{~mL}$ KHS (previouly gassed with $5 \% \mathrm{CO}_{2}+95 \% \mathrm{O}_{2}$ ) using 50-mL siliconized Erlenmeyer flask in the absence or presence of exogenous substrates $(2 \mathrm{mmol} / \mathrm{L}$ lactate $+0.2 \mathrm{mmol} / \mathrm{L}$ pyruvate or 2 $\mathrm{mmol} / \mathrm{L} \mathrm{L}$-glutamine $+0.2 \mathrm{mmol} / \mathrm{L}$ L-glutamate for PTs, $2 \mathrm{~m} \mathrm{mmol} / \mathrm{L}$ lactate $+0.2 \mathrm{mmol} / \mathrm{L}$ pyruvate for MTALs, and $2 \mathrm{mmol} / \mathrm{L}$ glucose for PCDs) in absence or presence of $2 \mathrm{mM} \mathrm{L}$ arginine. For each experimental condition, blanks $(T=0)$ were prepared at $4^{\circ} \mathrm{C}$ with the same tubular suspension, KHS, and substrates but were immediately deproteinized as described below. A 10-fold supraphysiological concentration of exogenous L-arginine was used to prevent a rapid depletion of L-arginine during the metabolic incubation and to enhance the level and the detection of the metabolites derived from L-arginine catabolism. Furthermore, to prove that L-arginine catabolism occured at physiological concentrations of L-arginine in PTs, a dose-response curve of urea/L-ornithine production was obtained in 2 experiments designed to present : $0,0.01,0.025,0.05,0.1,0.2,0.5,1,2,5$, and $10 \mathrm{mmol} / \mathrm{L} \mathrm{L}$-arginine to a suspension of PTs in the presence of $2 \mathrm{mmol} / \mathrm{L}$ lactate $+0.2 \mathrm{mmol} / \mathrm{L}$ pyruvate and incubated for 30 minutes at $37^{\circ} \mathrm{C}$. 
At the end of the incubation, the content of the flasks was deproteinized with $0.4 \mathrm{~mL} 20 \%$ perchloric acid (PCA); and $4.3 \mathrm{~mL}$ of the supernatant were neutralized with $0.3 \mathrm{~mL} 40 \% \mathrm{KOH}$. The following metabolites were measured enzymatically on the neutralized PCA extract [40, 41]: lactate, pyruvate, L-glutamine, L-glutamate, $\alpha$-ketoglutarate, L-aspartate, L-alanine, $\mathrm{NH}_{4}{ }^{+}$, glucose, urea, L-arginine. Therefore, all intracellular and extracellular metabolites were measured together, allowing to calculate net extraction and production of metabolites irrespectively of intracellular concentration or compartmentation.

To know whether L-ornithine was produced by AII during the metabolic incubation, the supernatant was analyzed by 2-dimensional thin-layer chromotography as described by Bremer et al. [42]. Each plate (cellulose thin-layer plate 10 x $10 \mathrm{~cm}$; Merck Frosst Canada, Kirkland, Quebec, Canada) was developed twice in solvant 1 (pyridine/dioxane/25\% ammonia/water $[35 ; 35 ; 15 ; 15, \mathrm{vol} / \mathrm{vol}])$ for 120 minutes, dried, and developed twice in solvant 2 ( $n$ butanol/acetone/acetic acid/water $[35 ; 35 ; 7 ; 23$, vol/vol]) for 60 minutes. The plate was sprayed with ninhydrin solution and dried. The spot of L-ornithine was identified and cut to quantify the amount of L-ornithine by using the ninhydrin colorimetric method [43]. Standard solutions of L-ornithine were analyzed in the same time to determine the concentration of Lornithine in the samples. In addition, we wanted to prove by another way that the positive ninhydrin-reactive substance was L-ornithine. A full high-performance liquid chromatography (HPLC) aminogram was performed from the supernatant of PT incubated with $2 \mathrm{mmol} / \mathrm{L} \mathrm{L}$ arginine. Amino acids were measured after phenylisothiocyanate derivatization [44] by reverse-phase HPLC (Waters Pico-Tag column, 0.39 X $15 \mathrm{~cm}, 38^{\circ} \mathrm{C}$ ) using a solvent system consisting of $140 \mathrm{mmol} / \mathrm{L}$ sodium acetate containing TEA $(0.5 \mathrm{~mL}$ TEA/L) and $60 \%$ aqueous $\mathrm{CH}_{3} \mathrm{CN}$. Detection at $254 \mathrm{~nm}$ allowed quantification, by peak surface comparison with internal and external standards, using a Spectra-Physic integrator model SP4270.

\subsection{Preparation of cytosolic and mitochondrial fractions by differential centifugation}

The whole renal cortex of one dog and the outer stripe of the outer medulla of female rats were dissected at $4^{\circ} \mathrm{C}$ under a stereomicroscope. The dissected tissue was rapidly immersed in a buffer composed of $250 \mathrm{mmol} / \mathrm{L}$ sucrose, $10 \mathrm{mmol} / \mathrm{L}$ Tris- $\mathrm{HCl}$, and $1 \mathrm{mmol} / \mathrm{L} \mathrm{Na} \mathrm{NDTA}_{2}$, ( $\mathrm{pH}$ 7.6) homogenized using a motor-driven Potter-Elvehjem glass homogeneizer with a loose-fitting Teflon pestle (Bellco Glass, Vineland, NJ) and centrifuged at $600 \mathrm{~g}$ for 10 minutes at $4^{\circ} \mathrm{C}$ to remove cell debris and the nuclear fraction. The supernatant (S1) was centrifuged at $12000 \mathrm{~g}$ for 15 minutes at $4^{\circ} \mathrm{C}$ to pellet the mitochondrial fraction. The supernatant (S2) was centrifuged at $128000 \mathrm{~g}$ for 60 minutes at $4^{\circ} \mathrm{C}$ (Optima TLA 100.2 
Ultracentrifuge, Beckman) to obtain proteins of the cytosolic fraction in the supernatant (S3). To wash the mitochondria, the pellet was resuspended 3-times in the same buffer and centrifuged $12000 \mathrm{~g}$ for $15 \mathrm{~min}$ at $4{ }^{\circ} \mathrm{C}$. The cytosolic fraction was submitted to a speed-vac evaporation to concentrate the proteins. Protein concentrations were determined using the Bradford protein assay [45]. Cytosolic proteins and purified mitochondria were dissolved in Laemmli buffer (62.5 mmol/L Tris-HCl [pH 6.8], 1\% sodium dodecyl sulfate [SDS], 10\% glycerol, $0.1 \mathrm{~mol} / \mathrm{L}$ dithioerythriol, and bromophenol blue [46]), heated at $95^{\circ} \mathrm{C}$ for 5 minutes, and immediately dipped in a bath maintained at $4{ }^{\circ} \mathrm{C}$.

\section{Western blot analyses}

Two hundred-microgram samples of soluble proteins were subjected to $9 \%$ SDSpolyacrylamide gel electrophoresis (PAGE) containing $0.1 \%$ SDS applying $6 \mathrm{~W}$ per gel $(14 \times 16 \mathrm{~cm})$. Twenty microliters of a protein ladder (Precision Plus Protein Standards; BioRad, Marnes la Coquette, France) were also loaded to verify the size of the protein of interest. Proteins were transferred to a polyvinylidene difluoride membrane $(0.45 \mu \mathrm{m}$, Immobilon-P; Millipore, St Quentin en Yvelines, France) at $150 \mathrm{~mA}$ for 90 minutes. Proteins were visualized on the membrane with Ponceau S solution. Immunoblots were washed twice for 15 minutes in 1x Tris-buffered salt Tween (TBST; $20 \mathrm{mmol} / \mathrm{L}$ Tris [pH 7.6], $137 \mathrm{mmol} / \mathrm{L} \mathrm{NaCl}$, $0.1 \%$ Tween 20) and immersed twice in a blocking solution consisting of $5 \%$ fat-free milk powder in 1x TBST for 30 minutes.

Immunoblots were incubated in 5\% fat-free milk in 1x TBST with the primary polyclonal rabbit antibodies raised against ASS (dilution 1:1000) [47], ASL (dilution 1:1000) [48], OAT (CovalAb, Villeurbanne, France, dilution 1:1000) [49], AII (CovalAb, dilution 1:500) [49], aconitase (dilution 1:10000) [50], and the monoclonal mouse antibody raised against the $\alpha$ subunit F1-ATP synthase (dilution 1:5000) [49]. The antibodies were incubated separately for 60 minutes. Afterward, the immunoblot was rinced 3-times for 15 minutes in 1x TBST and incubated for 60 minutes with either a peroxidase-conjugated anti-rabbit immunoglobulin $G$ (IgG) or a anti-mouse IgG secondary antibody (dilution 1:10000-1:20000) in 5\% fat-free milk in 1x TBST. The immunoblot was washed 3-times for 15 minutes in 1x TBST and antibody binding was revealed using chemiluminescence (ECL) Western blotting kit. The ECL detection was performed using Kodak X-MAT films. Low-exposure film was scanned using the ImagerMaster Total Lab version 2.01 program (Pharmacia, Orsay, France). The immunoblot was washed 2-times for 15 minutes in 1x TBST and incubated with a new antibody. 


\subsection{Chemicals}

Amino acids and substrates were purchased from Sigma Chemical (Montreal, Canada); and SDS, sucrose, glycerol, Tween 20, dithioerythriol, phenylmethylsulphonylfluoride, benzamidine, ponceau $\mathrm{S}$ solution, peroxidase-conjugated anti-rabbit and anti-mouse IgG secondary antibodies, X-MAT films were purchased from Sigma (Saint Quentin Fallavier, France). Enzymes for enzymatic determinations were from Boehringer (Manheim, Germany).

\subsection{Results and statistical analysis}

The plasma levels of amino acids are expressed in micromoles per liter (mean $\pm \mathrm{SE}, \mathrm{n}=5$ dogs). Given that blood was sampled in the aorta (A) and the renal vein (V) of each dog, V-A difference was calculated for each amino acid; and where appropriate, statistical differences were assessed using the non-parametric Wilcoxon test for paired data at the $95 \%$ level significance (StatView SE+Gr and StatView 5).

For the metabolic studies, PTs were incubated 30, 60, and 120 minutes. Given that plotting metabolic rates of PTs against incubation time revealed linearity up to 60 minutes for PTs, the data obtained at 120 minutes were discarded. To calculate the metabolic rate for each experimental condition and substrate, the data obtained at 30 minutes were multiplied by 2 and a mean value was calculated with the data abtained at 60 minutes. In contrast, for MTALs, we used the data obtained at 60 and 120 minutes to calculate a mean production per hour.

In Table 2 and 3, data are presented as micromoles of metabolites extracted (-) or produced (+) per gram wet weight and per hour (means $\pm \mathrm{SE}$ ). The data were analyzed using appropriate 2ways and 1-way analyses of variance (ANOVA) (SuperANOVA software, Abacus), and a $P<$ .05 was accepted as significant. The ANOVA was used to analyze simultaneously all the data of each protocol in order to examine statistically: (1) the effect of substrates (none, lactate, Lglutamine), (2) the effect of cationic amino-acid (none, L-arginine), and (3) the effect of the incubation times $(0,30,60$, and 120 minutes). The effect of experimental replication $(\mathrm{n}=4$ in Tables 1 and 2) was found not significant. Only the main effects are reported because the interactions found could be explained by obvious mechanisms and could distract the reader from the main point of the article. 


\section{RESULTS}

\subsection{Anabolism of L-arginine in the dog kidney}

This experiment was conducted to know whether the dog kidneys synthesize L-arginine from L-citrulline as in other mammals except the carnivores ones [13-18, 21]. This biochemical pathway requires the expression of ASS and ASL and the substrates L-citrulline and Laspartate. The concentration of plasma amino acids was measured in the renal vein (V) and aorta (A); and the renal balance (V-A) that reflects either a production and a release when the $\mathrm{V}$-A difference is positive or an extraction and a consumption when the V-A difference is negative was calculated for each amino acid. Given that 24 L-amino acids were simultaneously detected by HPLC, we present their plasma concentrations in Table 1 and comment briefly on the data below.

The plasma concentration of L-citrulline was $16 \pm 4 \mu \mathrm{mol} / \mathrm{L}$ higher in the aorta than that in the renal vein, indicating a significant uptake of L-citrulline by the kidney (Fig. 2; Wilcoxon, $P<$ .005). Concomitantly, the plasma concentration of L-arginine was significantly increased by 22 $\pm 4 \mu \mathrm{mol} / \mathrm{L}$ in the renal vein compared with that in the aorta and corresponded to de novo Larginine production (Fig. 2; Wilcoxon, $P<.005$ ). The disappearance in L-citrulline was statistically equal to the renal production of $\mathrm{L}$-arginine (Wilcoxon, $P=.9593$ ). The results prove that the anabolic pathway of L-arginine exists in dog kidneys. Similarly, the plasma concentration L-ornithine was $9 \pm 2 \mu \mathrm{mol} / \mathrm{L}$ higher in the renal vein than that in the aorta, revealing a renal production of L-ornithine by dog kidneys (Fig. 2; Wilcoxon, $P<.005$ ). As previously reported, the kidneys of rats [51] and dogs [52] produce L-serine. Our results confirm that L-serine synthesis occurred in the dog kidney inasmuch as the plasma concentration of L-serine was significantly enhanced by $85 \pm 31 \mu \mathrm{mol} / \mathrm{L}$ in the renal vein (Wilcoxon, $P<.005$ ). L-serine might originate in part from the disappearance of $40 \pm 16$ $\mu \mathrm{mol} / \mathrm{L}$ L-glycine from the arterial plasma (Wilcoxon, $P<.005$ ). The results also indicated that L-glutamine was highly consumed in the dog kidney, whereas high amounts of Lglutamate were released (Wilcoxon, $P<.005$ in both cases). Interestingly, the dog kidney is an important source of L-alanine since its plasma concentration in the renal vein was abruptly increased by $353 \pm 56 \mu \mathrm{mol} / \mathrm{L}$ (Wilcoxon, $P<.005$ ) compared with the arterial plasma. In addition, the V-A differences in L-taurine, L-threonine, L-asparagine, L-cystine, L-tyrosine, Lphenylalanine, L-lysine, and L-histidine concentrations were small and significantly positive suggesting a release/production from the dog kidney. Given that rat and mouse kidneys express cysteine sulfinate decarboxylase, the rate-limiting enzyme that forms L-taurine [53], our 
results suggest that the dog kidney might also synthesize L-taurine and express cysteine sulfinate decarboxylase. Concerning the low but significant release of other L-amino acids in the renal vein, it is conceivable that these L-amino acids originated from a significant catabolism of plasma proteins or peptides in the PTs [54].

\subsection{Expression of enzymes involved in L-arginine anabolism in the dog renal cortex}

This experiment was performed to know whether the renal cortex of dogs expresses ASS and ASL proteins. Given that ASS and ASL are cytosolic enzymes, the cytosolic fraction of the dog cortex was purified by differential centrifugation and isolated mitochondria were used as negative control. Given that the antibodies used were not directed against the dog enzymes, identification of ASS and ASL was based on the homology of amino acid sequences between species. Dog mitochondria were characterized by aconitase $(85 \mathrm{kDa})$ which is strictly located in the mitochondrial matrix (Fig. 3). The purity of the preparation was shown by the lack of aconitase in the cytosolic fraction (Fig. 3). The results clearly revealed that the expression of ASS and ASL proteins was restricted to the cytosolic fraction of the dog cortex (Fig. 3). Their molecular weights correponded approximatively to the predicted size of $44.3 \mathrm{kDa}$ for dog ASS (National Center for Biotechnology Information [NCBI]: XP_537813) and $51.7 \mathrm{kDa}$ for dog ASL (NCBI : XP_536832). The antibodies raised against the mouse ASS (NCBI : NP_031520) and rat ASL (NCBI : NP_067588) proteins well recognized the dog proteins.

\subsection{Catabolism of L-arginine in different nephron segments}

\subsubsection{Proximal tubules.}

All the metabolic processes presented below were linear for at least 60 minutes (Fig. 4), allowing the presentation of data as metabolic rates in Table 2. In the absence of substrates, the PTs used endogenous L-alanine, L-aspartate, and L-glutamate $(\approx 12 \mu \mathrm{mol} /[\mathrm{h}$ g wet weight)] and probably other endogenous L-amino acids such as L-arginine with regard to the low production of urea (Table 2, line 1). A small fraction of these L-amino acids were neoglucogenic because glucose accumulated $(\approx 3 \mu \mathrm{mol} /[\mathrm{h} \mathrm{g}$ wet weight $)]$, whereas the main fraction was oxidized to support the production of energy. Indeed, the high production of $\mathrm{NH}_{4}{ }^{+}$ indicated that L-amino acids were first desaminated before being catabolized and suggested that oxidation was the predominant metabolic pathway at play.

In the absence of exogenous L-arginine, the isolated tubules produced a very low amount of urea that was probably due to the intracellular storage of L-arginine. Indeed, the renal cortex of rats and rabbits contains higher levels of L-arginine than the blood and the other renal zones [55,56]; and PCT cells reabsorb the filtered amino acids including L-arginine [54,57]. In 
contrast, incubation of suspension cortical tubules with L-arginine led to a stoechiometric and reciprocal disappearance of L-arginine $(P<.001)$ and production of urea $(P<.001)$ (Table 2, line 2; Fig. 4A). The presence of exogenous substrates (lactate + pyruvate or L-glutamine + Lglutamate) did not affect this process. Quantitation of L-ornithine by ninhydrin demonstrated a net accumulation of L-ornithine $(P<.001)$, but not the amount predicted from L-arginine disappearance and urea production, suggesting further metabolism of L-ornithine (Table 2, line 2; Fig. 4B). The compound detected by the ninhydrin colorimetric method was also analyzed by HPLC to identify the L-amino acids arising from the degradation of L-arginine (Fig. 1). The HPLC analysis demonstrated a net accumulation of L-ornithine (retention time [RT], 11.91 minutes) but no L-proline (RT, 5.94 minutes) in the presence of L-arginine (RT, 5.34 minutes). In addition, a small peak corresponding to L-glutamate- $\gamma$-semialdehyde (RT, 11.51 minutes) was also observed (data not shown). Because the exogenous L-arginine was metabolized into L-ornithine and urea, the present data strongly support that an arginase activity was expressed in the cortical tubules and more probably in the cortical PTs (85\% PTs).

The partial catabolism of L-ornithine-derived from L-arginine was confirmed by the metabolic effects observed in presence of L-arginine as sole substrate : a net accumulation of L-glutamate $(P<.004)$ with secondary modest inhibition of glutaminase activity (EC, 3.5.1.2), leading to a net reduction of ammonia production $(P<.003)$ when no lactate could stimulate ammonia incorporation into L-glutamate (Table 2 , line 2). A stimulation of L-alanine accumulation $(P<$ .001) arising from the change in tissue L-glutamate content was also observed, specially in presence of a source of lactate + pyruvate (Table 2, line 4). The presence of L-arginine as a source of L-glutamate enhanced L-alanine accumulation. No change in L-aspartate metabolism was noted. These observations indicate a metabolism of L-ornithine through L-glutamate formation $(P<.004)$, occurring at a slower rate than the arginase flux (urea and L-ornithine accumulation). Glucose production was slightly inhibited by the presence of L-arginine $(P<$ $.015)$.

Only the analysis of the main effects analyzed by ANOVA are presented on Table 2. Indeed, the interactions found were fully expected: (1) the accumulation of glucose, ammonia, and Lglutamate as well as the uptake of substrates are different with the type of substrate used, leading to interactions $(P<.0001)$ between the factors incubation time and substrates; (2) accumulation of L-alanine was more marked in presence of lactate (source of pyruvate) and of L-arginine (source of L-glutamate) than in absence of lactate, leading to an interaction between the factors substrates and cationic amino-acids; and (3) the effect of L-arginine was slightly more marked at the period 60 to 120 minutes than that during the 0 to 60 minutes, leading to 
interactions $(P<.0001)$ between the factors incubation time and cationic amino acids factors for urea, L-ornithine, L-glutamate, and L-alanine. The F value of these interactions was considerably less than that calculated for the main effects.

The incubation of cortical tubules with increasing amounts of L-arginine led to a progressive increment in urea production of up to 1 to $2 \mathrm{mmol} / \mathrm{L} \mathrm{L}$-arginine. Beyond $2 \mathrm{mmol} / \mathrm{L} \mathrm{L}$-arginine, the rate of urea production was significantly inflected and reduced (Fig. 5). It can be estimated that $1 \mathrm{~g}$ of kidney cortex is capable of producing $40 \mu \mathrm{mol}$ of urea and $40 \mu \mathrm{mol}$ of L-ornithine per 30 minutes under maximal conditions (10 $\mathrm{mmol} / \mathrm{L} \mathrm{L}$-arginine) and around $5 \mu \mathrm{mol}$ of urea per 30 minutes under physiological conditions (100 $\mu \mathrm{mol} / \mathrm{L} \mathrm{L}$-arginine). If we consider that the cortical suspension contains approximately $85 \%$ PTs and 1 millimeter rat PCT is equivalent to $0.18 \mu \mathrm{g}$ protein [58], it can be deduced that dog PTs produced about $196 \mathrm{fmol}$ urea / ornithine per minutes per millimeter.

\subsubsection{Thick ascending limbs.}

Because the production of urea and AII activity is extremely low in the rat, mouse, cat, and Meriones shawii MTAL [34], the suspension of dog MTAL was incubated for 60 and 120 minutes to enhance L-arginine catabolism and the amount of urea produced. In the absence of substrates, extremely low levels of urea were detected, whereas the net production of $\mathrm{NH}_{4}{ }^{+}$ proved that endogenous L-amino acids were desaminated probably before being oxidized to sustain ATP production (Table 3, line 1). This process was decreased when adding lactate + pyruvate to the incubating medium (Table 3, line 3). Incubation of MTAL with $2 \mathrm{mmol} / \mathrm{L} \mathrm{L}$ arginine revealed that a very small amount of L-arginine was hydrolyzed with regard to the production of urea (Table 3, line 2). This process was not modified by the presence of exogenous metabolic substrates (lactate + pyruvate). These results suggest that MTALs express a very low arginase activity.

\subsubsection{Papillary collecting ducts.}

In 2 experiments, the suspensions of dog PCDs were incubated for 120 minutes for the same reason as described for MTALs. Incubation of PCDs with L-arginine led to no significant hydrolysis of L-arginine and no production of urea either in the absence or in the presence of glucose as substrate (data not shown). These results suggest that PCDs probably do not express arginase gene.

\subsection{Expression of enzymes catabolizing L-arginine and L-ornithine in the dog renal cortex}


Proteins of the renal cortex were analyzed by Western blot to prove that AII and OAT were expressed in dogs. The cytosolic and mitochondrial fraction of the dog renal cortex were separated by differential centrifugation. Mitochondria isolated from the outer stripe of the outer medulla of the female rat were used as a positive control because AII and OAT proteins are highly expressed in this renal zone [49]. As noted above and for the same reason, identification of the enzymes was based on the homology of amino acid sequences between species. As shown in Fig. 6, rat and dog mitochondria were characterized by the $\alpha$-subunit F1ATP synthase $(55 \mathrm{kDa})$, which is attached on the inner side of the inner membrane of the mitochondria. The lack of $\alpha$-subunit F1-ATP synthase in the cytosolic fraction proved the purity of the preparation. As expected, AII and OAT proteins were highly expressed in the rat mitochondria. On this basis, our results reveal that the renal cortex of dogs expressed AII (38 $\mathrm{kDa})$ and OAT $(48 \mathrm{kDa})$ proteins in the mitochondrial compartment. The molecular sizes of $\operatorname{dog}$ AII (NCBI : XP_866822 and XP_537488) and dog OAT (NCBI : XP_866064 and XP_535050) were similar to those found for the rat (NCBI NP_062041 and NP_071966; respectively). The antibodies raised against mouse and rat OAT and AII proteins well recognized the dog proteins, confirming the high level of identity between their amino acid sequences (CLUSTALW multiple alignment, AII : 84.5\% identity and OAT : $90.2 \%$ identity). 


\section{DISCUSSION}

The basic amino acids L-arginine and L-ornithine are of central importance in the catabolic and biosynthetic pathways as well as in physiological events in living cells and organisms. Larginine is nutritionally indispensable, serves for protein synthesis, and plays a number of critical physiological roles, including its participation in the production of nitric oxide, polyamines, creatine, and L-amino acids. Therefore, L-arginine homeostasis is balanced between its synthesis, consumption, and degradation.

In mammalian kidneys, L-arginine production requires L-citrulline and the enzymes ASS and ASL. However, in cats, which highly express ASS and ASL in their PTs [21], a faint synthesis of L-citrulline from L-glutamine and L-glutamate was due to the very low activities of OAT, carbamoyl phosphate synthase (EC 6.3.4.14), pyrroline-5-carboxylate synthase, and ornithine carbamoyl transferase (EC 2.1.3.3) in the enterocytes of their small intestine [59]. Consequently, the low level of L-citrulline in cat blood is incapable of sustaining an adequate production of L-arginine in the kidney to maintain L-arginine homeostasis [21]. In contrast, the dog arterial plasma exhibited high levels of L-citrulline $63 \pm 5 \mu \mathrm{mol} / \mathrm{L}$ [this article], $48.8 \pm 8.1$ $\mu \mathrm{mol} / \mathrm{L}$ [60], $64 \mu \mathrm{mol} / \mathrm{L}$ [61], and $30.8 \mu \mathrm{mol} / \mathrm{L}$ [15] compared with those of the cats. Given that the renal production of L-arginine is proportional to the level of L-citrulline [13,62], the plasma concentrations of L-citrulline in dogs are sufficient to sustain a significant production of L-arginine for body needs as known in other species [13,14,16-18]. L-arginine anabolism also depends on the level of ASS and ASL gene expression. Nevertheless, this point has never been documented in the dog kidney. For the first time, we prove that ASS and ASL were expressed in the cytosolic fraction of the dog renal cortex by identifying their proteins on immunoblots. Based on their molecular weight and immunological properties, the dog ASS and ASL proteins strongly resemble those of the mouse and rat as confirmed by the high level of identity between their amino acid sequences (CLUSTALW multiple alignment: ASS, 92.9\% identity and AS, 88.6\% identity, respectively). Although the localization of ASS and ASL

proteins were not performed in a suspension of dog PTs, it is known that the PTs are the most abundant tubules in the cortex $[58,63]$ and both enzymes are essentially expressed in the PCT of several species [20,23]. Moreover, the PCT is the privileged site of L-citrulline reabsorption [64]. Altogether, this study proves that under normal physiological conditions, the dog kidney extracted L-citrulline from the arterial blood ( $-16 \pm 4 \mu \mathrm{mol} / \mathrm{L})$ and, statistically, released equal amounts of L-arginine into the renal venous blood ( $+22 \pm 4 \mu \mathrm{mol} / \mathrm{L})$. Mongrel dogs and beagle exhibited high and quite similar arterial plasma concentration of L-arginine $(141 \pm 8 \mu \mathrm{mol} / \mathrm{L}$ 
[60] and $163 \pm 9$ to $177 \pm 12 \mu \mathrm{mol} / \mathrm{L}$ [15] for the former and $124 \pm 12 \mu \mathrm{mol} / \mathrm{L}$ for the latter [this study]). Noticeably, the sum L-arginine plus L-ornithine released in the renal vein is higher than L-citrulline consumed in the kidney. Several reasons are listed to explain this discordance : (1) Protein catabolism occurs in the dog kidney, and the molecules of L-arginine incorporated into proteins might be a source of L-arginine and L-ornithine derived from Larginine catabolism. This point is supported by the data from $\mathrm{Yu}$ et al. [15] who reported that the total L-arginine released from the kidney $(19 \mu \mathrm{mol} /[\mathrm{kg} \mathrm{h}])$ exceeded the $6.8 \mu \mathrm{mol} /(\mathrm{kg} \mathrm{h})$ that was formed from L-citrulline and released into the renal vein. (2) Methylation of Larginine residues of protein produces $\mathrm{N}^{\mathrm{G}}$-monomethylarginine, $\mathrm{N}^{\mathrm{G}}, \mathrm{N}^{\mathrm{G}}$-dimethylarginine (asymmetrical dimethylarginine); and $\mathrm{N}^{\mathrm{G}}, \mathrm{N}^{,}{ }^{\mathrm{G}}$-dimethylarginine (symmetrical dimethylarginine). Proteolysis of proteins releases free $\mathrm{N}^{\mathrm{G}}$-monomethylarginine and asymmetrical dimethylarginine, which are metabolized into methylamines and L-citrulline by $\mathrm{N}^{\mathrm{G}}, \mathrm{N}^{\mathrm{G}}$-dimethylarginine dimethylaminohydrolase (EC 3.5.3.18) [65]. Given that $\mathrm{N}^{\mathrm{G}}, \mathrm{N}^{\mathrm{G}}$ dimethylarginine dimethylaminohydrolase is expressed in PTs, the bulk of L-citrulline produced locally might be an additional source of L-arginine [66]. (3) Ornithine aminotransferase catalyzes a reversible reaction that leads to either L-glutamate or L-ornithine. At present, we do not know how the renal OAT of dogs works in vivo. It cannot be excluded that OAT produces L-ornithine from L-glutamine and L-glutamate.

Although several enzymes control L-arginine catabolism in the kidney, our attention was restricted to AII. In PTs, the substrate L-arginine can be endogenously produced from Lcitrulline or can enter the cells at least by the apical membrane of the rat PT (reabsorption) [67]. To prevent the endogenous production of L-arginine, suspensions of tubules were incubated without L-citrulline. In the presence of exogenous L-arginine, PTs produced a high amount of urea that was accompanied by an equimolar diminution of L-arginine and a nearly equimolar accumulation of L-ornithine. Given that the renal arginase is localized in mitochondria [35,68,69], our data support that L-arginine was also transported into mitochondria to be further metabolized. Our results showed that PTs expressed a high arginase activity compared with MTALs, whereas PCDs did not express this enzyme. The expression of an AII was clearly confirmed by analyzing on immunoblots mitochondrial proteins isolated from of the dog cortex ( $>85 \%$ PTs). Our results are in a good agreement with the report of Rabinowitz et al [70] that depicted an arginase activity almost exclusively in the renal cortex. Unfortunately, in our study, we omitted to test whether proximal straight tubules express an arginase activity. The distribution pattern of AII within the dog kidney strongly differs from those of rats and mice $[33,71]$, but exhibits a similarity with those of rabbits, guinea pigs, cats, 
and Meriones shawii, which expressed an arginase in their PCT [21,33,34]. The data obtained in dogs sustain the view that the renal distribution of AII is species specific. Given that the amino acid sequence of the dog AII (NCBI : XP_866822 and XP_537488) contains the IASSFGQTREGGHIVYD peptide sequence that shows $87.5 \%$ identity with the IASSFGQTREGGHIEC peptide sequence used to prepare our primary antibody and that a molecular weight of $38 \mathrm{kDa}$ was found for the dog arginase in mitochondria, the dog AII might strongly resemble those of mice [35] and rats [49].

Interestingly, in cells, several metabolic pathways are interconnected; and the presence or the absence of exogenous metabolites might modify the homeostasis of the end-product of these pathways. This is why we examined the metabolic consequences of L-arginine hydrolysis in a suspension of dog cortical PTs to integrate AII activity into a general physiological and metabolic framework. The metabolic behaviour of L-arginine was analyzed in detail to give an insight to (1) the metabolic fate of L-ornithine-derived from L-arginine hydrolysis and (2) the interaction between L-arginine catabolism and metabolites such as lactate and L-glutamine known to be also highly metabolized in this nephron segment (Fig. 1) [72,73]. In cortical PTs, the rate of L-arginine hydrolysis apparently exceeded that of L-ornithine appearance because L-ornithine accumulation in the incubating medium corresponded to 76 to $85 \%$ of the amount of L-arginine hydrolyzed. In addition, we observed that the plasma concentration of Lornithine was higher in the renal vein than that in the aorta, indicating that the dog kidney released L-ornithine in the bloodstream. We calculated that the dog PT produced about 282 nmol of L-ornithine per millimeter per day. This value is dramatically higher than the values found for the PCT of cats [21], guinea pigs [34], rabbits [33], and Meriones shawii [34]. Consequently, we proposed that, in the dog kidney, the function of AII might be to supply circulating L-ornithine for the body. Release of L-ornithine from the kidney has been also observed in humans [18].

The remaining $15 \%$ to $24 \%$ of L-ornithine derived from L-arginine can serve as precursor for putrescine, L-proline, and L-glutamate synthesis or can be oxidized to supply ATP for cellular functions. It is generally assumed that L-proline synthesis cannot occur in the kidney because the enzyme pyrroline-5-carboxylate reductase (EC 1.5.1.2) that converts 1-pyrroline-5carboxylate into L-proline is lacking. Our HPLC chromatogram clearly confirmed the lack of L-proline production by dog PTs (data not shown). The expression of ODC that converts Lornithine into putrescine remains undocumented in dog kidney. In contrast, L-ornithine can be transaminated by OAT (Fig. 1). However, given that the concentration of L-ornithine 
generated from L-arginine by AII is fairly small, the rate of L-ornithine transamination in the dog cortical PTs occurred at a relatively low rate. The identification of glutamate- $\gamma$ semialdehyde by HPLC in PTs incubated with L-arginine supported the view of L-ornithine transamination. Moreover, the existense of this pathway is strongly supported by revealing the expression of OAT protein in the dog renal cortex on immunoblots. The molecular weight of the dog OAT (48.3 $\mathrm{kDa})$ was similar to that of the female rat [49]. In addition, the amino acid sequence of the dog OAT (NCBI : XP_866064 and XP_535050) contains the 3 peptide sequences (SVATKKTIQGPPSSDY, IFERESKYGAHYHP, and IMLTIKAGEHGSTYG) that exhibited $87.5 \%, 100 \%$, and $92.8 \%$ identity, respectively to the 3 peptide sequences (SVATKKEQGPPSSEC, IFERESKYGAHNYHC, and CMLTIKPGEHGSTYG) used to prepare our primary OAT antibody.

The interaction between L-arginine catabolism and other metabolites is discussed in this section. The presence of L-arginine in the incubating medium modified L-glutamine metabolism in PTs. L-glutamine utilization $(-84.5$ vs $-71.4=13.1)$ and $\mathrm{NH}_{4}{ }^{+}$production $(136$ vs $112=24$ ) were significantly reduced, whereas L-glutamate accumulation was significantly increased $(25.4$ vs $28.6=3.2)$. Under our incubating conditions, $\mathrm{NH}_{4}{ }^{+}$originated from Lglutamine, L-glutamate, and L-amino acids produced during protein catabolism. In the presence of L-arginine, the decrease in $\mathrm{NH}_{4}{ }^{+}$production was about twice greater than that expected from L-glutamine utilization. To explain this result, we propose that L-arginine provoked a weak inhibition of phosphate-dependent glutaminase (EC 3.5.1.2) and glutamate dehydrogenase (EC 1.4.1.2) activities by an unknown mechanism. These 2 mitochondrial enzymes are involved in L-glutamine and L-glutamate catabolism and are expressed in the PT [72,74,75]. Interestingly, AII and OAT are also localized in the mitochondrial matrix $[35,49,68,69]$ and in the dog PT. To explain the concomitant decrease in L-glutamine utilization and L-glutamate accumulation, we hypothesized that a fraction of L-glutamate originated from the transamination of L-ornithine derived from L-arginine by OAT activity. In addition, the production of glutamate- $\gamma$-semialdehyde during the transamination step controlled by OAT might serve to produce a second molecule of L-glutamate (Fig. 1). Given that Lglutamate is known to be the most important inhibitor of kidney-type glutaminase [72], Lglutamate generated by OAT could negatively regulate phosphate-dependent glutaminase activity in the mitochondria.

Regarding the metabolic fate of L-glutamate produced by OAT, this amino acid serves either to synthesize L-glutamine or to regenerate $\alpha$-ketoglutarate for another transamination step. The synthesis of L-glutamine is controlled by the enzyme glutamine synthetase (EC: 6.3.1.2) that is 
expressed in the PT of the rat and rabbit kidneys [76]. In contrast to these species, the dog kidney does not express glutamine synthetase [77]. Consequently, the alternative route for Lglutamate is to undergo deamination by glutamate dehydrogenase to produce $\alpha$-ketoglutarate that can be (1) completely oxidized in the Krebs cycle to supply energy for the cells, (2) used to transaminate a new molecule of L-ornithine, (3) used by aspartate transaminase (EC 2.6.1.1) and alanine aminotransferase (EC 2.6.1.2), or (4) recycled for gluconeogenesis (Fig. 1). Although the carbons of $\alpha$-ketoglutarate can lead to the production of oxaloacetate and then to glucose in the gluconeogenic pathway, the carbons of L-ornithine derived from L-arginine did not contribute to glucose synthesis because the presence of L-arginine produced a modest inhibition of glucose synthesis in the presence of exogenous L-glutamine or lactate. This may be related to the increased level of L-glutamate modulating the intramitochondrial-limiting oxaloacetate concentration. The fact that L-alanine (with lactate) production was increased by L-arginine suggested that the increased in L-glutamate level was responsible for this finding, presumably through increased utilization of pyruvate towards amino acid synthesis. In the dog kidney, L-arginine is therefore not a major gluconeogenic L-amino acid. 


\section{ACKNOWLEDGMENTS}

This study was supported by a grant of the Medical Research of Canada. Dr O. Levillain held a grant from the Fondation de la Recherche Médicale, France. We acknowledge the technical assistance of Jacques Sénécal, Marie Christine Gougoux, and Gisèle Grenier.

The authors are indebted to Dr Heinrich Wiesinger (Interfakultäres Institut für Biochemie, Tuebingen, Germany), Dr Catherine Godinot (UMR 5534 CNRS, CGMC, Villeurbanne, France), Dr Bertrand Friguet (Laboratoire de Biologie et Biochimie Cellulaire du Vieillissement, EA 3106/IFR 117, Université Paris 7, France), and Dr Luke I. Szweda (Oklahoma Medical Research Foundation, Oklahoma city, OK) who kindly provided us the respective primary polyclonal rabbit antibodies raised against ASS and ASL, $\alpha$-subunit F1ATP synthase, and aconitase. 


\section{FIGURE LEGENDS}

Fig. 1 Relationship between the metabolic pathways of L-arginine, L-ornithine, and other amino acids; the Krebs cycle; and the gluconeogenesis pathway in dog cortical PTs. Enzymes are written in red, and the metabolites measured are written in green. In the Krebs cycle and gluconeogenesis, only the essential enzymatic steps are indicated. The red cross indicates that GS is not expressed in the dog kidney. The expression of ODC in the dog cortex is still unknown (dashed line). ALAT (EC 2.6.1.2) indicates alanine aminotransferase or alanine transaminase; $\alpha-\mathrm{kGDH}$ (EC 1.2.4.2), $\alpha$ ketoglutarate dehydrogenase; AspT (EC 2.6.1.1) aspartate transaminase; CS (EC 2.3.3.1), citrate synthase; GLDH (EC : 1.4.1.2) glutamate dehydrogenase; GS (EC 6.3.1.2) glutamine synthetase; LDH (EC 1.1.1.27) lactate dehydrogenase, PC (EC : 6.4.1.1), pyruvate carboxylase; PDG (EC: 3.5.1.2), phosphate dependant glutaminase; PEPCK (EC :4.1.1.49), phosphoenolpyruvate carboxykinase; P5C-R (EC: 1.5.1.2), 1-pyrroline-5-carboxylate reductase; P5C-DH (EC: 1.5.1.12), 1pyrroline-5-carboxylate dehydrogenase; $\mathrm{PDH} \quad$ (EC: 1.2.1.51), pyruvate dehydrogenase; PK (EC : 2.7.1.40), pyruvate kinase.

Fig. 2 Individual plasma concentrations of L-citrulline, L-arginine, and L-ornithine in the renal vein and aorta in the 5 dog studied.

When the concentration of plasma L-amino acid is higher in the aorta (closed square) than that in the renal vein (open square), the kidney extracted and metabolized the Lamino acid considered. In contrast, when the concentration of plasma L-amino acid is lower in the aorta than that in the renal vein, the kidney released and produced the Lamino acid considered. Detail : for L-ornithine, 2 dogs had similar concentrations in the aorta and renal vein.

Fig. 3 Expression of ASS and ASL in the dog cortex.

The cytosolic fraction and isolated mitochondria were purified by differential centrifugation. Two hundred micrograms of dog cytosolic and mitochondrial (used as negative control) proteins were subjected to 9\% SDS-PAGE containing 0.1\% SDS and analyzed by Western blotting. Each antibody (ASS, ASL, and aconitase) was incubated alone with the immunoblot. After rinsing, the immunoblot was incubated with the peroxidase-conjugated anti-rabbit IgG secondary antibody. Binding was revealed by ECL, and luminescence was monitored on X-ray films. Aconitase was 
used as marker of mitochondria. Cyto indicates cytosolic fraction; Mito, mitochondria.

Fig. 4 Urea (A) and L-ornithine (B) production as a function of the incubation time.

Suspensions of dog cortical tubules composed of more than $85 \%$ PTs were incubated with $2 \mathrm{mmol} / \mathrm{L}$ L-arginine in absence (closed squares) or presence of exogenous substrates $(2 \mathrm{mmol} / \mathrm{L}$ lactate $+0.2 \mathrm{mmol} / \mathrm{L}$ pyruvate [open circles] or $2 \mathrm{mmol} / \mathrm{L} \mathrm{L}$ glutamine $+0.2 \mathrm{mmol} / \mathrm{L}$ L-glutamate [closed circles]). Data are expressed as means \pm $\mathrm{SE} ; \mathrm{n}=4$ experiments. The metabolic processes were linear for at least 60 minutes.

Fig. 5 Dose-response curve of urea production as a function of L-arginine concentration. Suspensions of dog cortical tubules composed of more than $85 \%$ PTs were incubated with increasing concentrations of L-arginine $(0-10 \mathrm{mmol} / \mathrm{L})$ for a period of 30 minutes to prevent a sharp disappearance of L-arginine. Data are expressed as means; $\mathrm{n}=2$ experiments.

Fig. 6 Expression of AII and OAT in the dog cortex.

Mitochondria were separated from the cytosolic fraction by differential centrifugation. Two hundred micrograms of dog cytosolic and mitochondrial proteins and rat mitochondrial proteins (used as positive control) were subjected to 9\% SDS-PAGE containing $0.1 \%$ SDS and analyzed by using Western blot. Each of the following antibody was incubated alone with the immunoblot: AII, OAT, and $\alpha$-subunit F1-ATP synthase. After rinsing, the immunoblot was incubated with the appropriate peroxidase-conjugated anti-rabbit or anti-mouse IgG secondary antibody, revealed by ECL, and exposed to x-ray film. The $\alpha$-subunit F1-ATP synthase were used as marker of the mitochondrial fraction. 


\section{Figure 1}

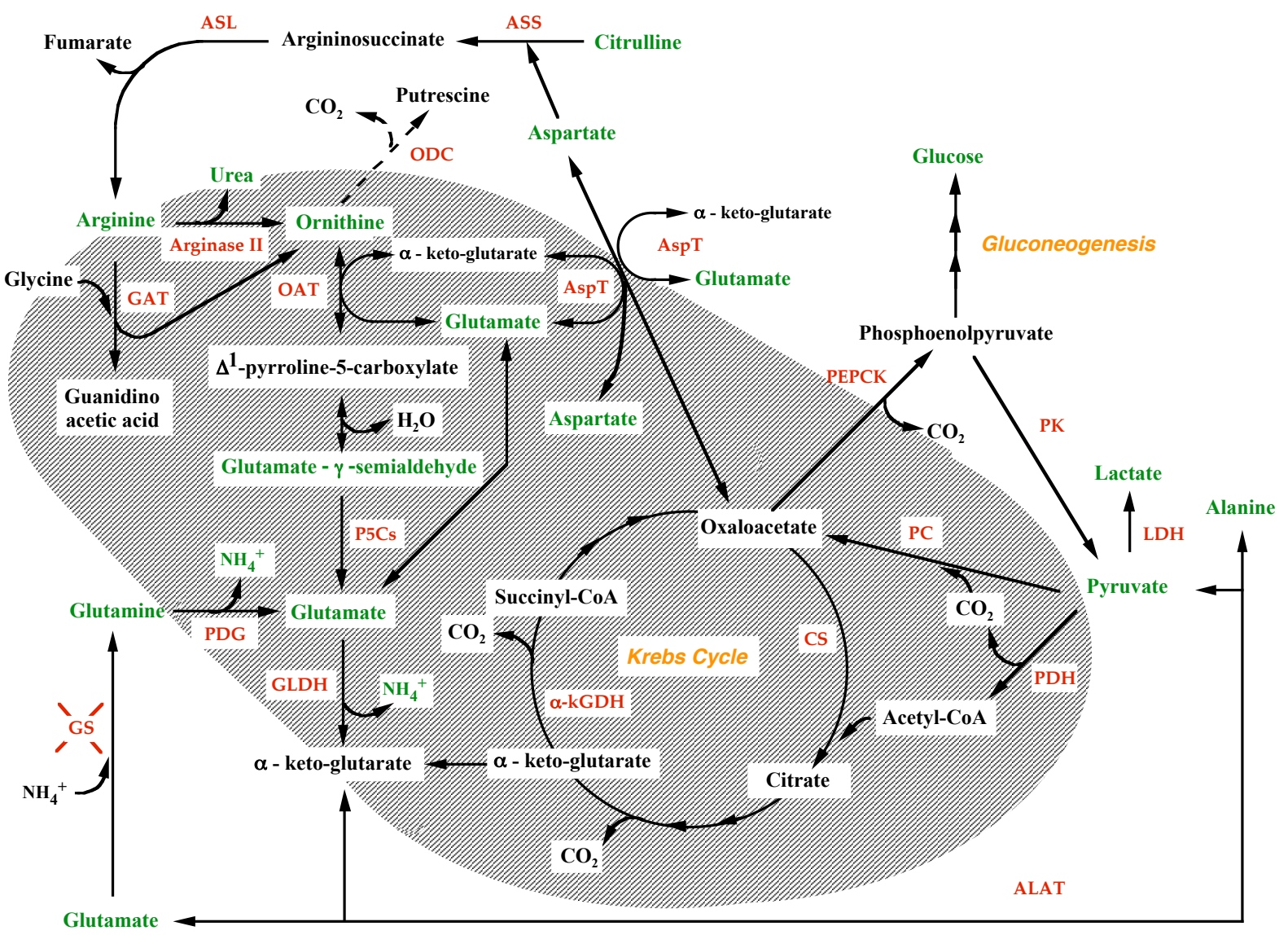




\section{Figure 1 bis}

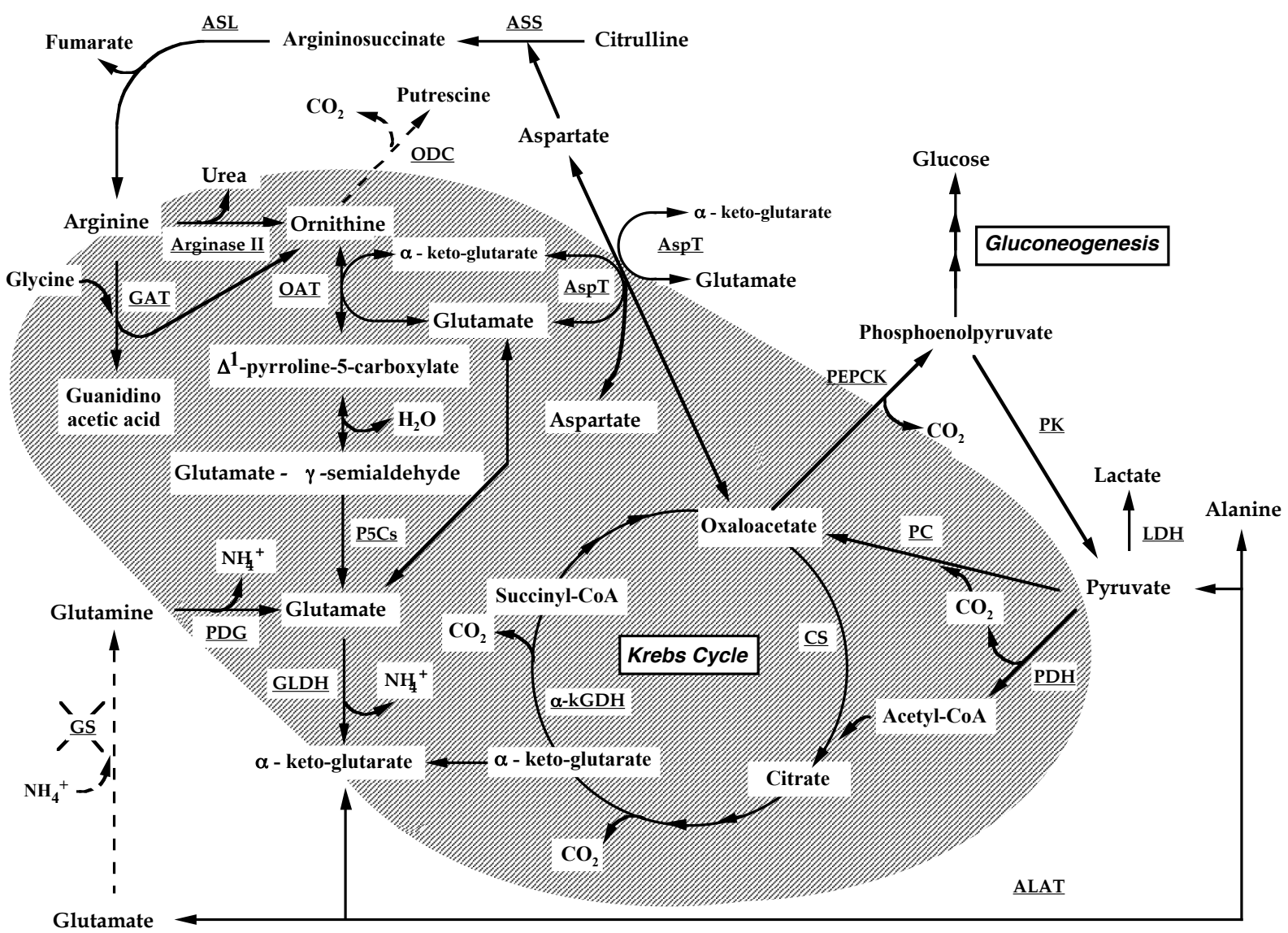


Figure 2

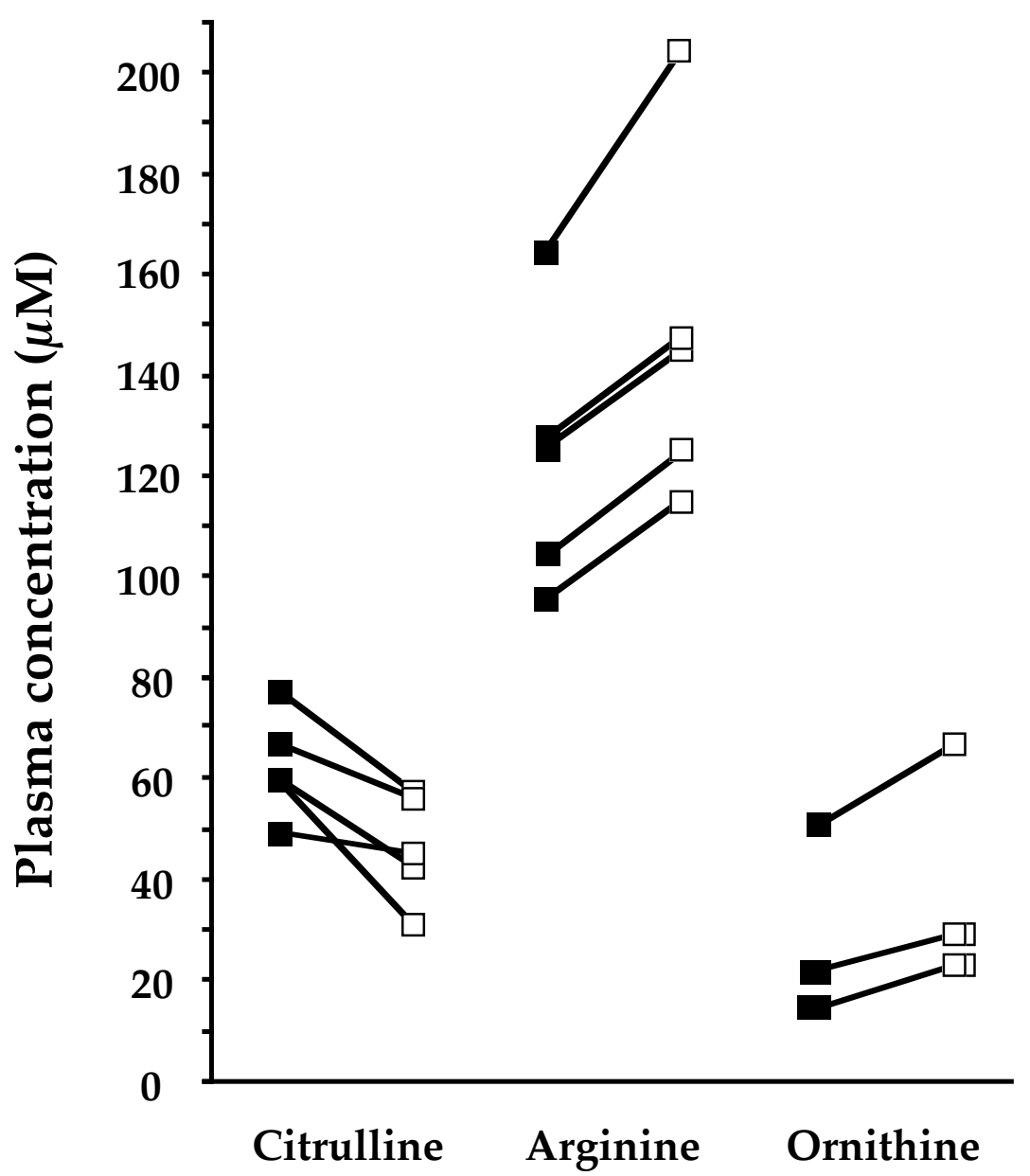


Figure 3

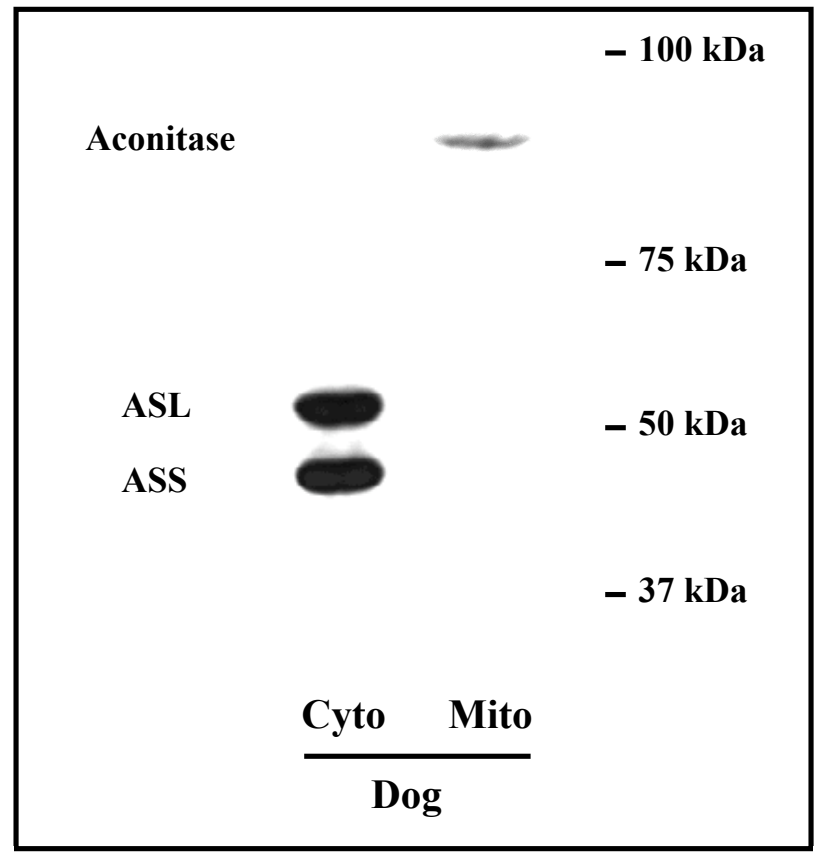


Figure 4
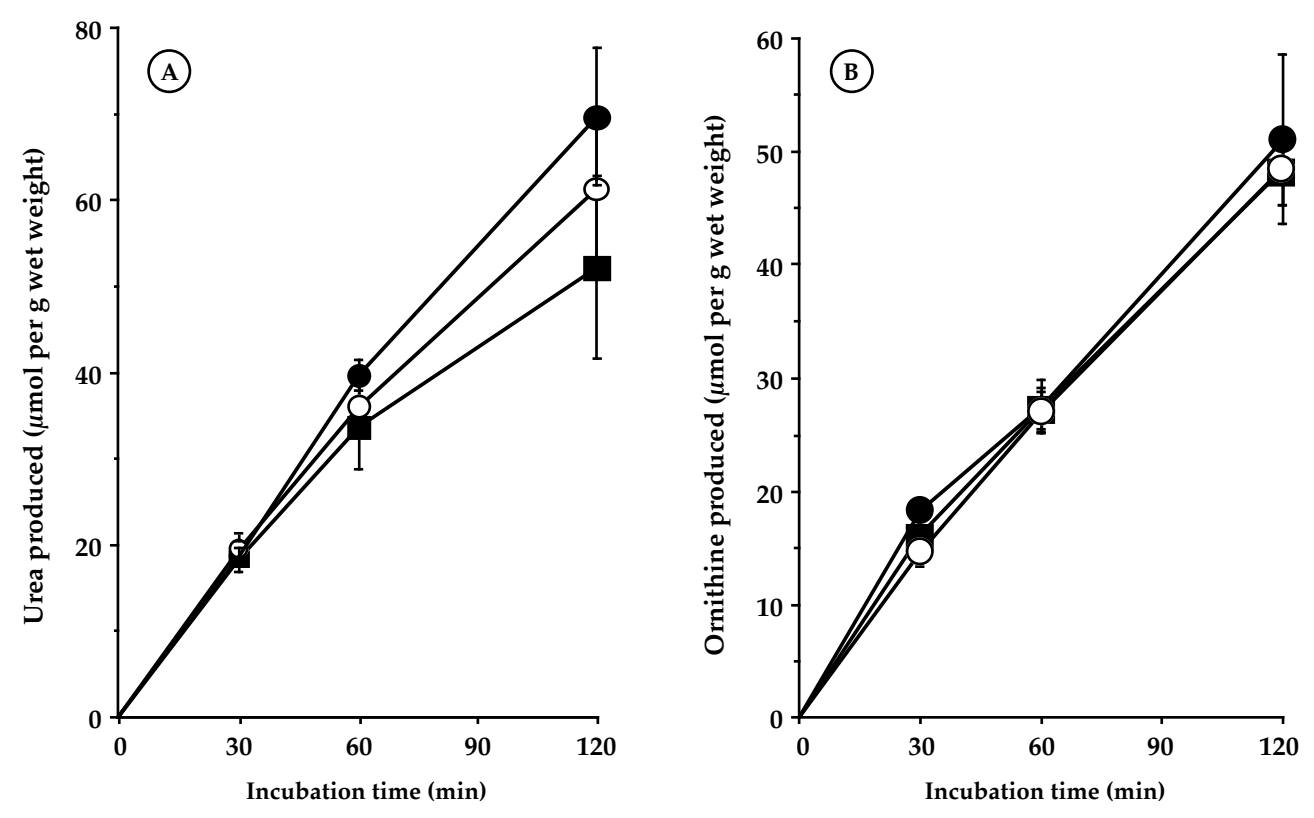
Figure 5

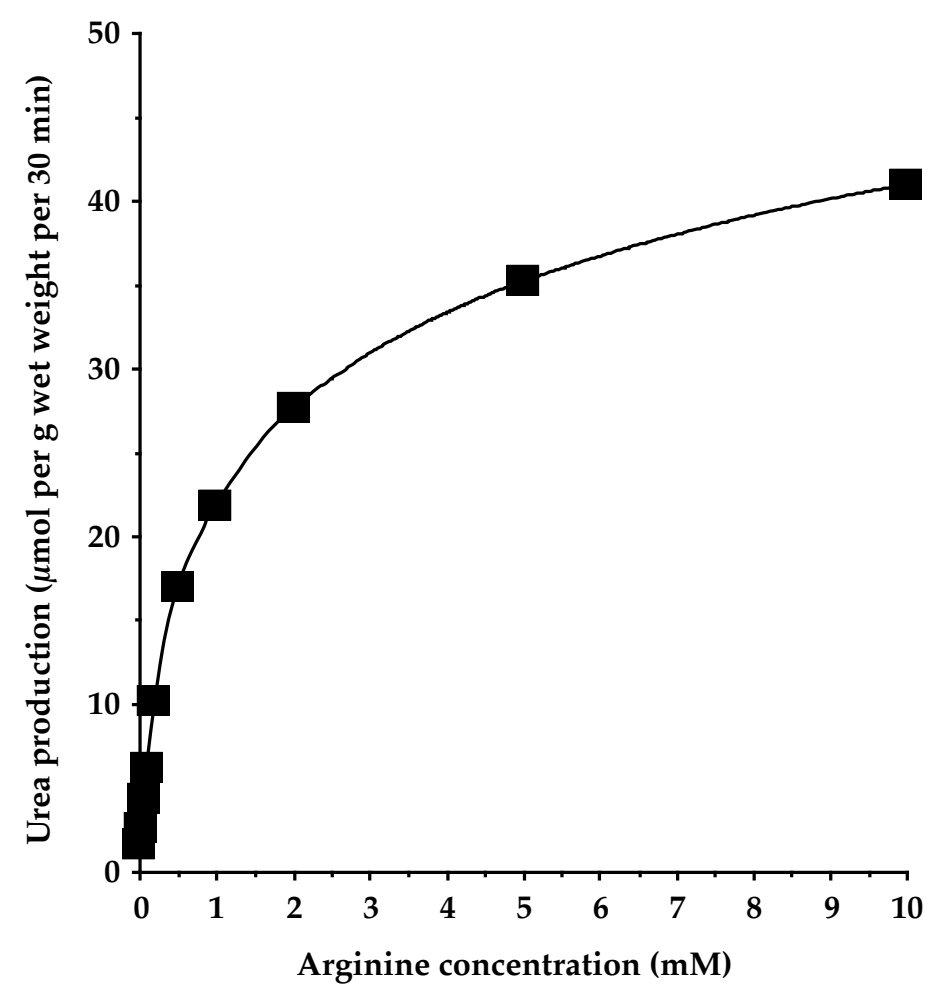


Figure 6

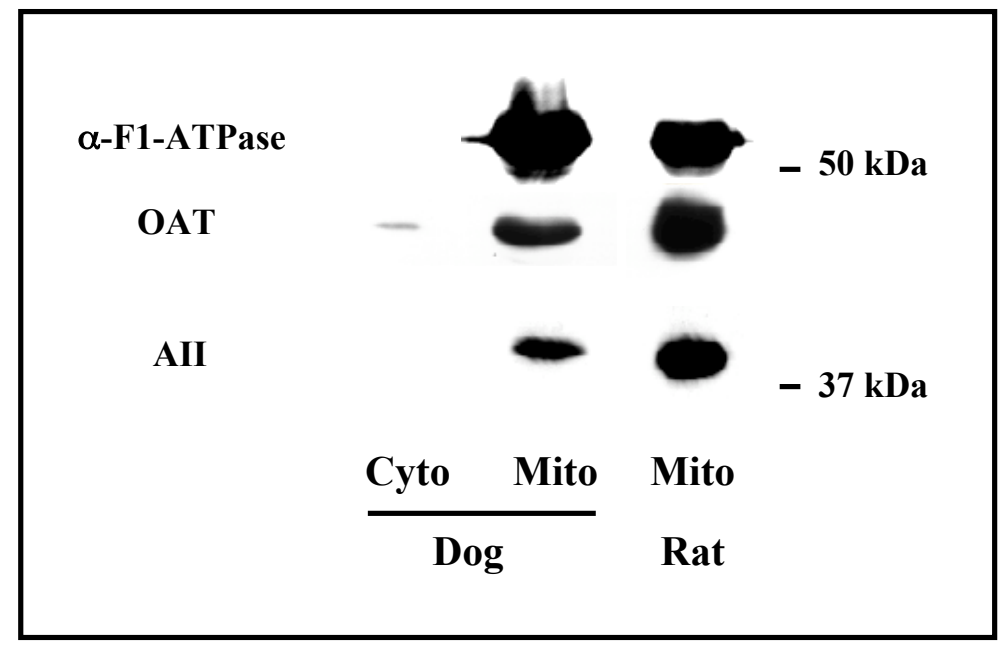




\section{REFERENCES}

[1] Wu GY, Morris SM Jr. Arginine metabolism: nitric oxide and beyond. Biochem J 1998; 336:1-17.

[2] Morris Jr SM. Recent advances in arginine metabolism. Curr Opin Clin Nutr Metab Care 2004; 7:45-51.

[3] Borsook H, Dubnoff JW. The conversion of citrulline to arginine in kidney. J Biol Chem 1941; 140:717-38.

[4] Featherston WR, Rogers QR, Freedland RA. Relative importance of kidney and liver in synthesis of arginine by the rat. Am J Physiol 1973; 224:127-9.

[5] Perez GO, Epstien M, Rietberg B, Loutzenhiser R. Metabolism of arginine by the isolated perfused rat kidney. Am J Physiol 1978; 235:F376-80.

[6] Goutal I, Fairand A, Husson A. Expression of the genes of arginine-synthesizing enzymes in the rat during development. Biol Neonate 1999; 76:253-60.

[7] Mistry SK, Greenfeld Z, Morris Jr SM, Baylis C. The "intestinal-renal" arginine biosynthetic axis in the aging rat. Mech Ageing Dev 2002; 123:1159-65.

[8] Morris Jr SM, Sweeney Jr WE, Kepka DM, O'brien WE, Avner ED. Localization of arginine biosynthetic enzymes in renal proximal tubules and abundance of mRNA during development. Ped Res 1991; 25:151-4.

[9] Rogers QR, Freedland RA, Symmons RA. In vivo sythesis and utilization of arginine in the rat. Am J Physiol 1972; 223:236-40.

[10] Morris Jr SM, Moncman CL, Holub JS, Hod Y. Nutritional and hormonal regulation of mRNA abundance for arginine biosynthetic enzymes in kidney. Arch Biochem Biophys $1989 ; 273: 230-7$.

[11] Yu Y, Terada K, Nagasaki A, Takiguchi M, Mori M. Preparation of recombinant argininosuccinate synthetase and argininosuccinate lyase: expression of the enzymes in rat tissues. J Biochem 1995; 117:952-7.

[12] Natesan S, Reddy SR. Compensatory changes in enzymes of arginine metabolism during renal hypertrophy in mice. Comp Biochem Physiol B 2001; 130:585-95.

[13] Dhanakoti SN, Brosnan JT, Herzberg GR, Brosnan ME. Renal arginine synthesis: studies in vitro and in vivo. Am J Physiol Renal Physiol 1990; 259:E437-42.

[14] Bouby N, Hassler C, Parvy P, Bankir L. Renal synthesis of arginine in chronic renal failure: in vivo and in vitro studies in rats with 5/6 nephrectomy. Kidney Int 1993; 44:676-83. 
[15] Yu YM, Burke J, Tompkins RG, Martin R, Young VR. Quantitative aspects of interorgan relationships among arginine and citrulline metabolism. Am J Physiol Endocrinol Metab 1996; 34:E1098-109.

[16] Luiking YC, Hallemeesch MM, Vissers YL, Lamers WH, Deutz NE. In vivo whole body and organ arginine metabolism during endotoxemia (sepsis) is dependent on mouse strain and gender. J Nutr 2004; 134:2768S-74S; discussion 2796S-97S.

[17] Boelens PG, van Leeuwen PA, Dejong CH, Deutz NE. Intestinal renal metabolism of Lcitrulline and L-arginine following enteral or parenteral infusion of L-alanyl-L$[2,15 \mathrm{~N}]$ glutamine or L-[2,15N]glutamine in mice. Am J Physiol Gastrointest Liver Physiol 2005; 289:G679-85.

[18] Tizianello A, De Ferrari G, Garibotto G, Gurreri G, Robaudo C. Renal metabolism of amino acids and ammonia in subjects with normal renal function and in patients with chronic renal insufficiency. J Clin Invest 1980; 65:1162-73.

[19] Dhanakoti SN, Brosnan ME, Herzberg GR, Brosnan JT. Cellular and subcellular localization of enzymes of arginine metabolism in rat kidney. Biochem J 1992; 282:36975.

[20] Levillain O: Renal arginine synthesis in mammals. In: Pandalai SG, editor. Recent res dev physiol, vol. 1. Trivandrum: Research Signpost; 2003, p. 67-83.

[21] Levillain O, Parvy P, Hus-citharel A. Arginine metabolism in cat kidney. J Physiol London 1996; 491:471-7.

[22] Levillain O, Hus-citharel A, Morel F, Bankir L: Arginine synthesis in mouse and rabbit nephron: localization and functional significance. Am J Physiol Renal Fluid Electrolyte Physiol 1993; 264:F1038-45.

[23] Miyanaka K, Gotoh $T$, Nagasaki A, Takeya M, Ozaki M, Iwase $K$, et al.: Immunohistochemical localization of arginase II and other enzymes of arginine metabolism in rat kidney and liver. Histochem J 1998; 30:741-51.

[24] Porembska Z, Baranczyk A, Jachimowicz J. Arginase isoenzymes in liver and kidney of some mammals. Acta Biochim Pol 1971; 18:77-85.

[25] Pietkiewicz J, Bryla J. Comparison of influence of 2-oxoglutarate and glutamate on arginase activities in liver and kidney-cortex of rabbit, Oryctolagus cuniculus. Comp Biochem Physiol B 1996; 115:393-8.

[26] Kochakian CD, Stettner CE. Effect of testosterone propionate and growth hormone on the arginase and phosphatases of the organs of the mouse. Am J Physiol 1948; 155:2624.

[27] Morris Jr SM, Bhamidipati D, Kepka-Lenhart D. Human type II arginase: Sequence analysis and tissue-specific expression. Gene 1997; 193:157-61.

[28] Robinson RR, Schmidt-Nielsen B. Distribution of arginase within the kidneys of several vertebrate species. J Cell Comp Physiol 1963; 62:147-57. 
[29] Aminlari M, Vaseghi T. Arginase distribution in tissues of domestic animals. Comp Biochem Physiol B 1992; 103:385-9.

[30] Gotoh T, Araki M, Mori M. Chromosomal localization of the human arginase II gene and tissue distribution of its mRNA. Biochem Biophys Res Commun 1997; 233:487-91.

[31] Jenkinson CP, Grody WW, Cederbaum SD. Comparative properties of arginases. Comp Biochem Physiol B 1996; 114:107-32.

[32] Mullins Von Dreele M, Banks RO. Urea synthesis in the canine kidney. Renal Physiol 1985; 8:73-9.

[33] Levillain O, Hus-citharel A, Morel F, Bankir L. Localization of urea and ornithine production along mouse and rabbit nephrons: functional significance. Am J Physiol Renal Fluid Electrolyte Physiol 1992; 263:F878-85.

[34] Levillain O, Hus-citharel A: Distribution of arginase along the mammalian nephron. In: De Deyn PP, Marescau B, Qureshi IA, Mori A, editors. Guanidino compounds: 2: John Libbey \& Compagny; 1996, p. 77-85.

[35] Levillain O, Balvay S, Peyrol S. Localization and differential expression of arginase II in male and female mouse kidney. Pflugers Archiv 2005; 449:491-503.

[36] Petrun NM. [Activity of glycine amidinotransferase and its isoforms in dog kidney tissue normally and in acute renal insufficiency]. Ukr Biokhim Zh 1974; 46:51-3.

[37] Gross MD, Eggen MA, Simon AM, Van Pilsum JF. The purification and characterization of human kidney L-arginine:glycine amidinotransferase. Arch Biochem Biophys 1986; 251:747-55.

[38] McGuire DM, Gross MD, Elde P, Van Pilsum JF. Localization of L-arginine-glycine amidinotransferase protein in rat tissues by immunofluorescence microscopy. $\mathrm{J}$ Histochem Cytochem 1986; 34:429-35.

[39] Takeda M, Nakayama S, Tomino Y, Jung KJ, Endou H, Koide H. Heterogeneity of transamidinase activity and creatine content along the rat nephron. In: De Deyn PP, Marescau B, Stalon V, Qureshi IA, editors. Guanidino compounds in biology and medicine. London: John Libbey \& Company; 1992, p. 153-7.

[40] Tejedor A, Noel J, Vinay P, Boulanger Y, Gougoux A. Characterization and metabolism of canine proximal tubules, thick ascending limbs, and collecting ducts in suspension. Can J Physiol Pharmacol 1988; 66:997-1009.

[41] Noel J, Vinay P, Laprade R, Gougoux A. BBM H+-ATPase activity in the dog kidney: modulation by substrate availability. Kidney Int 1990; 37:529.

[42] Bremer HJ, Duran M, Kamerling JP, Przyrembel H, Wadman SK. Chemical methods for detection, quantitation, and identification of amino acids in body fluids. In: Bremer HJ, Duran M, Duran M, Kamerling JP, Przyrembel H, Wadman SK, editors. Disturbances of 
amino acid metabolism: clinical chemistry and diagnosis, Urban and Schwarzenberg; Germany, 1981, p. 421-42.

[43] Moore S, Stein WH. Photometric ninhydrin method for use in the chromatography of amino acids. J Biol Chem 1948; 176:367-88.

[44] Heinrikson RL, Meredith SC. Aminoacid analysis by reverse phase high-performance liquid chromatography: Precolumn derivatization with phenylisothiocyanate. Anal Biochem 1984; 136:65-74.

[45] Bradford MM. A rapid and sensitive method for the quantitation of microgram quantities of protein utilizing the principle of protein-dye binding. Anal Biochem 1976; 72:248-54.

[46] Laemmli UK. Cleavage of structural proteins during the assembly of the head of bacteriophage T4. Nature 1970; 227:680-5.

[47] Schmidlin A, Kalbacher H, Wiesinger H. Presence of argininosuccinate synthetase in glial cells as revealed by peptide-specific antisera. Biol Chem 1997; 378:47-50.

[48] Bolla T, Kalbacher H, Vogel D, Wiesinger H. Argininosuccinate lyase: generation of antisera against peptide sequences of the rat brain enzyme and immunochemical studies on glial cells. Biol Chem 1999; 380:S95

[49] Levillain O, Hus-Citharel A, Garvi S, Peyrol S, Reymond I, Mutin M, et al. Ornithine metabolism in male and female rat kidney: mitochondrial expression of ornithine aminotransferase and arginase II. Am J Physiol Renal Physiol 2004; 286:F727-38.

[50] Bulteau AL, Ikeda-Saito M, Szweda LI. Redox-dependent modulation of aconitase activity in intact mitochondria. Biochemistry 2003; 42:14846-55.

[51] Pitts RF, Damian AC, MacLeod MB. Synthesis of serine by rat kidney in vivo and in vitro. Am J Physiol 1970; 219:584-9.

[52] Pitts RF, MacLeod MB. Synthesis of serine by the dog kidney in vivo. Am J Physiol $1972 ; 222: 394-8$.

[53] Reymond I, Bitoun M, Levillain O, Tappaz M. Regional expression and histological localization of cysteine sulfate decarboxylase mRNA in the rat kidney. J Histochem Cytochem 2000; 48:1461-8.

[54] Silbernagl S. The renal handling of amino acids and oligopeptides. Physiol Rev 1988; 68:911-1007.

[55] Silbernagl S, Volker K, Dantzler WH. Compartmentation of amino acids in the rat kidney. Am J Physiol Renal Fluid Electrolyte Physiol 1996; 270:F154-F63.

[56] Levillain O, Marescau B, De Deyn PP. Renal handling of guanidino compounds in rat and rabbit. J Physiol London 1997; 499:561-70.

[57] Pfaller W, Sibernagl S. Cellular localization of L-arginine reabsorption in proximal tubules of rat kidney cortex. Pflügers Arch 1975; 360:189-92. 
[58] Pfaller W, Rittinger M. Quantitative morphology of the rat kidney. Int J Biochem 1980; $12: 17-22$.

[59] Rogers QR, Phang JM. Deficiency of pyrroline-5-carboxylate synthase in the intestinal mucosa of the cat. J Nutr 1985; 115:146-50.

[60] Landis ME, Ray EC, Gloviczki P, Miller VM. Effects of dietary L-arginine on structure and function of flow-restricted vein grafts. J Vasc Surg 2001; 33:829-39.

[61] Juhr NC, Brand U, Riedel E. Plasma amino acid concentrations in aggressive dogs. Berl Munch Tierarztl Wochenschr 2005; 118:95-100.

[62] Levillain O, Hus-citharel A, Morel F, Bankir L. Localization of arginine synthesis along rat nephron. Am J Physiol Renal Fluid Electrolyte Physiol 1990; 259:F916-23.

[63] Kaissling B, Kriz W. Structural analysis of the rabbit kidney. In: Advances in anatomy embryology and cell biology, Berlin: Springer-Verlag; 1979.

[64] Kettner A, Silbernagl S: Renal handling of citrulline. In: Dzurik R, Lichardus B, Guder. W, Dzurik R, Lichardus B, Guder. W, editors. Kidney metabolism and function. Dordrecht: Martinus Nijhoff Publishers; 1985, p. 51-60.

[65] Ogawa T, Kimoto M, Sasaoka K. Purification and properties of a new enzyme, NG, NGdimethylarginine dimethylaminohydrolase, from rat kidney. J Biol Chem 1989; 264:10205-9.

[66] Tojo A, Welch WJ, Bremer V, Kimoto M, Kimura K, Omata M, et al. Colocalization of dimethylating enzymes and NOS functional efects of methylarginines in rat kidney. Kidney Int 1997; 52:1593-601.

[67]. Silbernagl S, Deetjen P. L-arginine transport in rat proximal tubules. Pflügers Arch 1972; 336:79-86.

[68] Gotoh T, Sonoki T, Nagasaki A, Terada K, Takiguchi M, Mori M. Molecular cloning of cDNA for nonhepatic mitochondrial arginase (arginase II) and comparison of its induction with nitric oxide synthase in a murine macrophage-like cell line. FEBS Lett 1996; 395:119-22.

[69] Shi O, Kepka-Lenhart D, Morris Jr SM, O'Brien WE. Structure of the murine arginase II gene. Mamm Genome 1998; 9:822-4.

[70] Rabinowitz L, Gunther RA, Shoji ES, Freedland RA, Avery EH. Effects of high and low protein diets on sheep renal function and metabolism. Kidney Int 1973; 4:188-207.

[71] Levillain O, Hus-citharel A, Morel F, Bankir L. Production of urea from arginine in pars recta and collecting duct of the rat kidney. Renal Physiol Biochem 1989; 12:302-12.

[72] Kovacevic Z, McGivan JD. Mitochondrial metabolism of glutamine and glutamate and its physiological significance. Physiol Rev 1983; 63:547-605. 
[73] Manillier C, Vinay P, Lalonde L, Gougoux A. ATP turnover and renal response of dog tubules to $\mathrm{pH}$ changes in vitro. Am J Physiol 1986; 251:F919-32.

[74] Wright PA, Knepper MA. Phosphate-dependent glutaminase activity in renal cortical and medullary tubule segments. Am J Physiol Renal Fluid Electrolyte Physiol 1990; 259:F961-70.

[75] Wright PA, Knepper MA. Glutamate dehydrogenase activities in microdissected rat nephron segments: effects of acid-base loading. Am J Physiol Renal Fluid Electrolyte Physiol 1990; 259:F53-9.

[76] Burch HB, Choi S, McCarthy WZ, Wong PY, Lowry OH. The location of glutamine synthetase within the rat and rabbit nephron. Biochem Biophys Res Comm 1978; 82:498-505.

[77] Lemieux G, Baverel G, Vinay P, Wadoux P. Glutamine synthetase and glutamyltransferase in the kidney of man, dog, and rat. Am J Physiol 1976; 231:1068-73. 